\title{
Combination of interferon-gamma and autophagy inhibitor as a therapeutic approach in oral squamous cell carcinoma
}

\section{Zhi-hang Zhou}

Ninth People's Hospital, Shanghai Jiao Tong University School of Medicine

\section{Tong-Chao Zhao}

Ninth People's Hospital, Shanghai Jiao Tong University School of Medicine

Si-yuan Liang

Ninth People's Hospital, Shanghai Jiao Tong University School of Medicine

Dong-wang Zhu

Ninth People's Hospital, Shanghai Jiao Tong University School of Medicine

\section{Zhi-yuan Zhang}

Ninth People's Hospital, Shanghai Jiao Tong Unviersity School of Medicine

\section{Wu-tong Ju}

Ninth People's Hospital, Shanghai Jiao Tong University School of Medicine

\section{Lai-ping Zhong ( $\square$ zhonglp@hotmail.com )}

Ninth People's Hospital, Shanghai Jiao Tong University School of Medicine

\section{Research}

Keywords: Oral squamous cell carcinoma; Interferon-gamma; Chloroquine; Autophagy; Apoptosis

Posted Date: May 22nd, 2020

DOl: https://doi.org/10.21203/rs.3.rs-30028/v1

License: (9) (i) This work is licensed under a Creative Commons Attribution 4.0 International License. Read Full License 


\section{Abstract}

Background: Former clinical trials and experimental research have indicated that interferon-gamma (IFNy) therapy does not achieve an ideal effect in solid tumors. Autophagy has been associated with tumor chemoresistance. The aim of this study was to explore the efficacy of IFNY and autophagy inhibitor in the combination treatment of oral squamous cell carcinoma (OSCC).

Method: IFNY-induced apoptosis was evaluated by the expression of relative proteins (cleaved-PARP and caspase-3) and flow cytometry. IFNY-induced autophagy was assessed by the expression of Beclin1, LC3B, and P62. The synergistic effect of IFNY and autophagy inhibitor (chloroquine) was evaluated in vitro and in vivo.

Findings: IFNY induced anti-proliferation, apoptosis, and autophagy in OSCC cells. Autophagy-related protein 5 (ATG5) was a key feature in IFNy-induced autophagy flux. IFNy and chloroquine had obvious synergistic effects on cellular growth inhibition and apoptosis promotion in OSCC cells and xenograft models.

Interpretation: Our findings suggest that IFNy-induced autophagy plays a cellular protective role, and blocking autophagy flux can promote IFNY-mediated OSCC cell apoptosis. The combination of IFNY and autophagy inhibitors represents a novel strategy for OSCC therapy.

\section{Background}

Oral squamous cell carcinoma (OSCC) is a common malignant tumor that occurs in the oral and maxillofacial region and has approximately 300,000 new cases worldwide each year [1,2]. Despite the progress achieved in radical surgical resection with proper reconstruction and postoperative radiotherapy/chemoradiotherapy, the 5-year survival rate has remained at $50 \%$ to $60 \%[3,4]$ and even lower in patients with locally advanced lesions. Consequently, there is an urgent need to explore effective OSCC therapeutic strategies.

Macroautophagy (autophagy or 'self-eating') is a lysosome-mediated process whereby cells degrade organelles and macromolecules and recycle cellular waste [5]. Accumulating evidence suggests that autophagy can both suppress and promote tumor functions in cancer progression $[6,7]$. On the one hand, the initial stages of tumorigenesis can be inhibited by autophagy [8] and on the other, autophagy could nurture established cancers [9-11]. Yang et al. [12] revealed the mechanism of how autophagy promotes pancreatic tumor growth via p53 alternation. In research relating to OSCC, autophagy was considered as crucial for either nurturing cancer cells $[13,14]$ or initiating programmed cell death $[15,16]$. Accordingly, the inhibition of autophagy may be a potential strategy for OSCC treatment.

Studies in interferon-gamma (IFNY) have demonstrated an anti-tumor effect in several tumors, including those in colorectal [17], gastric [18], and cervical [19] cancers. Recent findings suggest that members of the IFN family synergize with traditional anti-tumor treatment for OSCC through several mechanisms, 
including augmenting various immune functions [20]. However, IFNy therapy alone does not achieve an ideal effect on established tumors [17-19], which may reflect an adaptive resistance. Studies of chemoresistance in brain, gastric, and ovarian cancers suggest that autophagy plays a key role [21-23].

Herein, autophagy co-activated by IFNy is considered to be a cancer-promoting factor, which provides a potential strategy for combined inhibition therapy. In our present study, we first demonstrate autophagy and apoptosis induced by IFNY in OSCC cells. The ATG5 molecule was found to be necessary for IFNYinduced autophagy. Furthermore, IFNy and chloroquine (CQ) exhibited clear synergistic anti-tumor effects in vitro and in vivo. This study supports the combined application of autophagy inhibitors and IFNy in the clinical therapy of OSCC.

\section{Materials And Methods}

\subsection{Culture system}

HN4, HN6, HB96, and CAL27 cell lines were used in our study. The HB96 cell line was established from our in vitro cellular carcinogenesis model of OSCC. HN4 and HN6 cell lines were provided as a gift from the National Institutes of Health (USA). The HN4 cell line was derived from tongue squamous cell carcinoma. Cell line HN6 was established from pharyngeal squamous cell carcinoma. The tongue squamous cell carcinoma cell line CAL27 was purchased from ATCC (Manassas, VA, USA). These cell lines were cultured in complete DMEM (Gibco, Carlsbad, CA, USA), supplemented with $10 \% \mathrm{FBS}, 1 \%$ penicillin-streptomycin, and $1 \%$ glutamine. Cells were maintained in a humidified $5 \% \mathrm{CO}_{2}$ atmosphere at $37^{\circ} \mathrm{C}$.

\subsection{Cell proliferation assay}

To assess the cytotoxicity of IFNy, OSCC cells were seeded in 96-well flat-bottom plates in triplicate at a density of $1 \times 10^{4}$ cells $/ \mathrm{ml}$, supplied with different concentrations IFNY. A cell proliferation assay was performed using 3-(4,5-dimethylthiazol-2-yl)-2,5-diphenyltetrazolium bromide (MTT) solution $(0.5 \mathrm{mg} / \mathrm{ml})$. The plates were incubated in a humidified incubator at $37^{\circ} \mathrm{C}$ for $2 \mathrm{~h}$. The absorbance was measured at $450 \mathrm{~nm}$.

\subsection{Colony formation assay}

To evaluate the influence of IFNy on colony formation, HN4 and CAL27 cells were seeded in 24-well plates at approximately $1 \times 10^{3}$ cells/well and cultured in complete medium with $200 \mathrm{ng} / \mathrm{ml} \mathrm{IFNy}$ for $48 \mathrm{~h}$. Then the medium was replaced by complete DMEM for $6 \mathrm{~d}$. Plates were finally washed with PBS twice, fixed with $4 \%$ paraformaldehyde for $30 \mathrm{~min}$, and stained with $0.5 \%$ crystal violet for $5 \mathrm{~min}$. The counting of colonies was performed using Image $\mathrm{J}$ software.

\subsection{Real-time PCR assay}


The purity and concentration of the RNA were assessed by using a NanoDrop 2000/2000C spectrophotometer at wavelengths of 260/280 nm. A PrimeScript ${ }^{\text {TM }}$ RT Reagent Kit (TaKaRa Biotechnology) was used to reverse transcribe RNA into CDNA. The resultant CDNA was used as a template in a TB Green ${ }^{\circledR}$ Premix Ex Taq ${ }^{\text {TM }}$ Kit (TaKaRa Biotechnology) master mix and qPCR reactions were performed on a StepOnePlus ${ }^{\text {TM }}$ Real-Time PCR System. The human primer sequences were as follows: GAPDH forward: 5'-CCTCTGACTTCAACAGCGAC-3' and reverse: 5'-

TCCTCTTGTGCTCTTGCTGGC-3'; ATG7 forward: 5'-AGAACATGGTGCTGGTTTCC-3' and reverse: 5'CATCCAGGGTACTGGGCTAA-3'; P62 forward: 5'-CCGTGAAGGCCTACCTTCTG-3' and reverse: 5'TCCTCGTCACTGGAAAAGGC-3'; BECN1 forward: 5'-GTGGCTTTCCTGGACTGTGT-3' and reverse: 5'CACTGCCTCCTGTGTCTTCA-3'; ATG5 forward: 5'-TGCAGATGGACAGTTGCACA-3' and reverse: 5'CCACTGCAGAGGTGTTTCCA-3'.

\subsection{Western blot analysis}

Proteins were extracted from OSCC cells treated with $0,2,20$, or $200 \mathrm{ng} / \mathrm{ml} \mathrm{IFNy} \mathrm{for} 0,12,24$, and $48 \mathrm{~h}$, or from OSCC cells stimulated with $200 \mathrm{nM}$ IFNy combined with or without CQ for $48 \mathrm{~h}$. The membranes were blocked in 5\% skim milk in $1 \times$ TBST (Tris-buffered saline with Tween 20) at room temperature for 1 $\mathrm{h}$ and then incubated with primary antibodies ( $\beta$-actin, 1:1000; cleaved-PARP, 1:1000; caspase-3, 1:1000; ATG5, 1:1000; P62, 1:1000; LC3B II, 1:1000; STAT1, 1:1000) overnight at $4^{\circ} \mathrm{C}$. The membranes were then incubated with fluorescent-based anti-mouse or anti-rabbit IgG secondary antibodies (7076 and 7704, Cell Signaling Technology, USA) at a 1:10000 dilution for $1 \mathrm{~h}$ at room temperature. Immunoreactive bands were detected using enhanced chemiluminescence. The observation and analysis of immunoreactive bands were performed using the Odyssey Infrared Imaging System (LI-COR Biosciences, USA).

\subsection{Immunofluorescence analysis}

OSCC cells were fixed and permeabilized with $0.1 \%$ Triton X-100 (Sigma-Aldrich, St Louis, MO, USA) for 5 min. After blocking with $1 \%$ BSA-PBS for $1 \mathrm{~h}, 0.5 \mathrm{mg} / \mathrm{ml}$ of 4',6-diamidino-2-phenylindole was used to stain the nuclei of cells. The BioTek Cytation 3 Cell Imaging Reader was used to visualize and acquire immunofluorescence images. The number of LC3B-I/II puncta was determined by Image J software.

\subsection{Cell transfection}

OSCC cells were seeded into a 24-well plate according to the manufacturer's instructions. Small interfering RNA (siRNA, $100 \mathrm{nM}$ ) was transfected using Lipofectamine 3000 (Invitrogen, Carlsbad, CA, USA). Treatments were administered $24 \mathrm{~h}$ after transfection. The sequences of the ATG5 siRNA were \#1, 5'-GGAAUAUCCUGCAGAAGAATT-3', \#2, 5'-AGAAUAUAUCAGACAACGATT-3' and \#3, 5'AUCGGAAACUCAUGGAAUATT-3'.

\subsection{Immunohistochemistry}


To retrieve antigen, tumor slices were heated in a water bath at $100^{\circ} \mathrm{C}$ with EDTA buffer $(\mathrm{pH}=10.0)$ for 20 min. The primary antibodies were as shown below: LC3B II (CST, Danvers, MA, USA), P62, and Ki67 (Abcam, Cambridge, MA, UK). Immunohistochemistry and image analysis were performed to assess the mean optical density for Ki67, LC3B II, and P62 in vivo.

\subsection{Flow cytometry analysis}

HB96, HN4, and CAL27 cells were treated with IFNy for different durations (0, 24, and $48 \mathrm{~h})$ and with different concentrations $(0,2,20$, and $200 \mathrm{ng} / \mathrm{ml})$. OSCC cells (adherent and floating) were collected and analyzed with flow cytometry analysis using an Annexin V-FITC/PI Apoptosis Detection Kit (BD Biosciences, San Diego, CA, USA). The analysis was performed using a BD FORTASA flow cytometer (BD Biosciences, San Diego, CA, USA) and Flow Jo software.

\subsection{Autophagic flux assay}

HB96, HN4, and CAL27 cells were seeded into glass-bottom dishes. After $12 \mathrm{~h}, \mathrm{OSCC}$ cells were transfected with the GFP-mRFP-LC3 construct. Then IFNy (200 ng/ml) and CQ (Sigma-Aldrich) were added. The cells were washed twice in ice-cold PBS, fixed, mounted with histological mounting medium (Histomount, USA), and observed using an LSM510 confocal laser microscope (Carl Zeiss, Dresden, Germany).

\subsection{Transmission electron microscopy}

HB96, HN4, and Cal27 cells were fixed in 4\% paraformaldehyde in $0.1 \mathrm{M} \mathrm{PBS}(\mathrm{pH}=7.4)$ and washed in 0.1 $\mathrm{M}$ PBS. The cells were then fixed for $2 \mathrm{~h}$ with $1 \% \mathrm{OsO}_{4}$ dissolved in $0.1 \mathrm{M}$ PBS and dehydrated with a progressive series of ethanol (50-100\%) and permeated with epoxypropane. A Poly/Bed 812 kit (Polysciences, Warrington, PA, USA) was used to embed the sample. The samples were then embedded and polymerized in an electron microscope oven (TD-700, Dosaka, Japan) at $65^{\circ} \mathrm{C}$ for $24 \mathrm{~h}$ in pure fresh resin. Sections approximately 200-250 nm thick were stained with toluidine blue (Sigma-Aldrich, T3260) and then stained twice with 6\% uranyl acetate (EMS, $20 \mathrm{~min}$ ) and lead citrate (Fisher, $10 \mathrm{~min}$ ) for comparison. The samples were prepared and analyzed by JEM 1230 transmission electron microscopy (JEOL, Akishima, Tokyo) at $60 \mathrm{kV}$, and micrographs were obtained at $\times 5000$ and $\times 20,000$ magnification.

\subsection{Animal study}

SPF BALB/c nude mice (nu/nu, 4 weeks old, weighing approximately $20 \mathrm{~g}$ ) were purchased from Shanghai experimental animal center (Shanghai, China) and placed in the SPF facility of the Ninth People's Hospital, Shanghai Jiao Tong University, China. All laboratory procedures were approved by the laboratory animal care and use committee of the hospital. The xenograft model of the tumor in nude mice was established with CAL27 cells. In brief, $1 \times 10^{6}$ cells were subcutaneously injected with a diameter of $5 \mathrm{~mm}$, the animals received various treatment regimens: (a) control (0.9\% saline, i.p); (b) IFNy (10,000 IU per day, i.p); (c) CQ (30 mg/kg per day, i.p); (d) IFNy and CQ. Tumor size was monitored twice a week. 
Tumor volume was calculated using the formula length $\times$ width ${ }^{2} / 2$. After three weeks, the mice were killed and the tumor tissue was resected. Tumor tissue and organ parts were immobilized and embedded in paraffin. Tissue sections ( $4 \mathrm{~mm}$ ) were stained with hematoxylin and eosin. Terminal deoxynucleotide transferase dUTP notch end marker (TUNEL) was used to detect apoptotic cells.

\subsection{Statistical analysis}

All data were presented as the means \pm standard deviation (SD). GraphPad Prism version 7 (GraphPad Software, San Diego, CA, USA) was used to process the initial data and plot the results. Statistical analyses were performed with SPSS 13.0 software for Windows (SPSS Inc., Chicago, IL, USA). Student's ttest and one-way analysis of variance were used to evaluate the difference. The difference was considered significant at $\mathrm{P}<0.05$.

\section{Results}

\subsection{IFNY exhibited anti-proliferation activity and induces apoptosis in OSCC cells}

To evaluate the function of IFNY on OSCC cell proliferation and viability, MTT and colony formation assays were performed. IFNy exerted cytotoxicity in a time- and dose-dependent manner in HB96, HN4n, and CAL27 cells (Fig. 1A). In addition, the treatment of IFNY $(200 \mathrm{ng} / \mathrm{ml})$ for 8 days effectively attenuated the colony-forming capacity of HB96 and CAL27 cells (Fig. 1B). As shown in Fig. 1C and D, IFNY upregulated the cleaved-PARP and caspase-3 expression in a time-dependent manner in the HB96, HN4, and CAL27 cells. Flow cytometry assays support the above results, given that the proportion of Annexin Vpositive cells increased in a time- and dose-dependent manner after IFNy treatment (Fig. 1E and F).

\subsection{IFNY-induced autophagy in OSCC cells}

As shown in Fig. 2A and B, Beclin 1 and LC3B II expression increased in the IFNy-treated HB96, HN4, and CAL27 cells in a time- and dose-dependent tendency. P62 level was analyzed to determine whether the autophagosome up-regulation observed after IFNy treatment was caused by an increase of autophagic activity or a reduced turnover of autophagosomes. P62 was hydrolyzed when OSCC cells were treated with IFNy, demonstrating IFNy-induced autophagy. In accordance with western blot results (Fig. 2C), the distribution of LC3B II puncta also increased in the IFNy-treated OSCC cells compared with untreated control. Furthermore, we examined the morphology of the HB96, HN4, and CAL27 cells after IFNY induction by transmission electron microscopy (TEM). As shown in Fig. 2D, IFNY activated autophagy flux by increasing the formation of the initial sequestering compartment (the phagophore), the number of autophagosomes often containing multivesicular and multilamellar structures, and autolysosomes. Herein, our data indicated that IFNy induced autophagy in OSCC cells.

\subsection{IFNY-induced autophagy via ATG5 signaling in OSCC cells}


A set of autophagy-related genes (ATGs) was involved in the dynamic membrane-rearrangement reactions of autophagy. Among these genes, Beclin1, ATG5, and ATG7 represent the major regulators of the classical autophagy pathway in mammalian cells [24]. Using real-time PCR assays (Fig. 3A), we found that ATG5 mRNA expression increased significantly after IFNy treatment in HB96, HN4, and CAL27 cells. Moreover, the suppression of ATG5 expression using siRNAs (Fig. 3C) in the context of IFNY treatment (Fig. 3B and D) decreased Beclin 1 and LC3B II expression and increased P62 protein levels. These results suggested that ATG5 was required for IFNY-induced autophagy in OSCC cells. Moreover, silencing ATG5, the key regulator of autophagy, significantly enhanced the anti-tumor effects of IFNY using FACS (Fig. 3E), indicating that autophagy inhibitors might synergize with IFNY in the treatment of OSCC.

\subsection{CQ inhibits IFNY-induced autophagy in OSCC cells and synergizes with the anti-tumor effects of IFNY}

Based on previous results, CQ treatment caused the accumulation of both P62 and LC3B II. Consistent results are shown in Fig. 4A. Furthermore, an autophagy flux assay (Fig. 5) was performed in the HN4 and CAL27 cells treated with IFNy using a tandem fluorescent-tagged LC3B reporter plasmid (GFP-mRFPLC3B) [25]. The yellow fluorescence puncta represented the merging image of green and red fluorescence in autophagosomes, which indicated impaired autophagy. The red fluorescence puncta alone after fusion represented complete autophagic flux. Quantification of red (mRFP+ GFP-) and yellow (mRFP+ GFP+) puncta per cell indicates that IFNy increased autophagy flux (red and yellow puncta). CQ resulted in the accumulation of yellow puncta (hence autophagosomes) induced by IFNY.

CQ could also synergize IFNY-mediated anti-tumor effects in OSCC cells. As shown in Fig. 4A, compared with the IFNy-treated group, the combined application of IFNY and CQ significantly up-regulated the expression of caspase-3 and cleaved-PARP proteins. Flow cytometry assays support the above results (Fig. 4B). The proportion of Annexin V-positive cells increased after the combination treatment. Thus, the combined application of IFNY and CQ had a synergistic effect in OSCC cells.

\subsection{Enhanced anti-tumor effect of IFNy treatment when combined with CQ in vivo}

OSCC xenografts in nude mice were used to confirm the in vitro results. As shown in Fig. 6A and B, compared with the group treated with a single agent, the tumor volume in the combination treatment group was significantly reduced $(P<0.01)$. According to the TUNEL assay (Fig. $6 C$ ), IFNY up-regulated apoptosis in vivo, especially when combined with CQ. Furthermore, immunohistochemistry (Fig. 6D) showed a reduction of Ki67, a protein relative to proliferation. In accordance with the in vitro results, CQ resulted in the accumulation of both LC3B and P62 proteins. In summary, IFNy can induce autophagy and exhibit a synergistic effect with CQ on suppressing tumor growth in vivo (Fig. 6E).

\section{Discussion}

In this study, we demonstrated that IFNy simultaneously induced apoptosis and autophagy, and the attenuation of autophagy also synergized the OSCC cell apoptosis mediated by IFNY. IFNY-induced 
autophagy might partly explain the limited effect of IFNy in solid tumors. Moreover, we demonstrated a synergistic anti-tumor effect in the combination of IFNY and CQ. This finding might provide the experimental evidence to support the clinical use of combination treatment with IFNy and autophagy inhibitors in OSCC.

IFNy is a crucial cytokine in anti-tumor immunity, although a pro-tumorigenic function is also found under certain circumstances [26, 27]. In accordance with former research [26, 27], our in vitro experiment also confirmed the cytotoxicity of IFNY and the effective suppression of colony formation in OSCC cells. IFNY may up-regulate the function of immune cells (increased MHC class I expression, antigen responsive genes, and costimulatory molecules). IFNy is also capable of inducing the apoptosis of cancer cells via different mechanisms. Notably, IFNy, either alone or in combination with other cytokines, can induce cellular stress in selected tumor cells, leading to cell death or senescence [28-30]. Accordingly, IFNy has been taken into clinical trials for cancer treatment [31-33]. In our study, results of western blot analysis reveal IFNY-induced up-regulation of caspase-3 and cleaved-PARP protein expression, in a dose- and timedependent manner in vitro. FACS also indicate increasing apoptosis in the OSCC cells, especially with Annexin V. This evidence suggests that IFNY might be a potential drug in OSCC treatment.

However, former clinical trials of IFNY have failed to support the effectiveness of IFNY in malignant tumors. Schiller et al. have reported a good prognosis in patients with melanoma in phase II/III clinical trials of IFNy [34]. Unfortunately, they failed to detect the efficacious effects of IFNy, as the response rate was only $5 \%$, with significant side-effects [34]. This evidence suggests that only patients with early-stage or disseminated cancer could benefit from IFNy treatment [34]. It seems that this phenomenon shares something in common with autophagy, which is important in tumor progression. In accordance with our hypothesis, a former study demonstrates that IFNY induces both apoptosis and autophagy in Atf6-/- mice [35]. However, there is no evidence testifying this phenomenon in human cancer lines in vitro or in vivo. In our present study, in vitro and in vivo experimental processes were performed to verify IFNY-induced autophagy in OSCC. Since IFNY has not yet been approved in the therapy of most solid tumors, the autophagy activation in OSCC tissues has not been improved. Therefore, our study is the first to demonstrate that IFNy induces autophagy in OSCC, providing a possible mechanism to explain the limited effect of IFNy therapy in solid tumors.

Autophagy can both promote and inhibit tumor growth and the roles of autophagy vary in different contexts [36]. A cluster of ATGs is involved in the dynamic membrane-rearrangement reactions of autophagy[37]. Former research reported that the knockdown of ATGs, such as ATG5, synergized with chemotherapy in the efficient elimination of cancer cells [38, 39]. Herein, autophagy inhibition via the genetic silencing of ATG5 may contribute to the therapy of advanced cancer. According to our results, genetic silencing of ATG5 could inhibit IFNy-mediated autophagy via the LC3B pathway. Moreover, FACS also reveals that the silencing of ATG5 synergizes IFNy-induced apoptosis in vitro, demonstrating the cytoprotective role of autophagy during IFNy treatment and potential strategy of OSCC treatment by IFNY combined with an autophagy inhibitor. 
Despite the complex process of autophagy and the challenges of the treatment strategy, some pharmacologic autophagy inhibitions have been used in clinical trials [36]. Bryant et al. [40] have confirmed that CQ, as an autophagy inhibitor, could promote the effect of ERK inhibitor in pancreatic cancer treatment by attenuating the resulting autophagy of ERK-inhibition. Accordingly, CQ is chosen in our study, and the results demonstrate its synergistic effect with IFNy in anti-tumor activity. The strong evidence provided by the CQ results supports the launch of a clinical trial to assess the efficiency of IFNY in combination with an autophagy inhibitor in OSCC. Furthermore, our present results demonstrate that CQ sensitizes the OSCC cells to enhance IFNy induced apoptosis both in vitro and in vivo.

It is worth noting that increasing evidence has shown a positive relationship between IFNY and PD-L1 expression [41]. Kim et al. [41] have demonstrated that IFNy produced by T-cells could up-regulate exosomal PD-L1 expression, which promotes tumor growth through immune escape in non-small cell lung cancer. Unfortunately, the side-effect of IFNy in immune escaping has not been considered in this research. We are looking forward to exploring the relative tasks in future investigations.

\section{Conclusion}

In summary, we have demonstrated that IFNy significantly induces autophagy in OSCC. The inhibition of autophagy by the autophagy inhibitor can enhance the anti-tumor effects of IFNY in OSCC. This study provides a new strategy to enhance the efficacy of IFNY in the treatment of established cancer and may encourage the combined use of an autophagy inhibitor and IFNY in the treatment of OSCC.

\section{List Of Abbreviations}

Interferon-gamma (IFNY)

Oral squamous cell carcinoma (OSCC)

Autophagy-related protein 5 (ATG5)

\section{Declarations}

\section{Declaration of competing interests}

The authors confirm that there are no conflict of competing interest to declare.

\section{Ethics approval and consent to participate}

SPF BALB/c nude mice (nu/nu, 4 weeks old, weighing approximately $20 \mathrm{~g}$ ) were purchased from Shanghai experimental animal center (Shanghai, China) and placed in the SPF facility of the Ninth People's Hospital, Shanghai Jiao Tong University, China. All laboratory procedures were approved by the laboratory animal care and use committee of the hospital. 


\section{Consent for publication}

Not applicable.

\section{Availability of data and materials}

The datasets used and analyzed during the current study available from the corresponding author on reasonable request

\section{Acknowledgement}

Funding: This work was supported by National Natural Science Foundation of China (81972525 and 81672660), Shanghai Municipal Education Commission (17SG18), Shanghai Municipal Commission of Health and Family Planning (2018BR41), Program of Shanghai Academic/Technology Research Leader (19XD1422300) and Joint PhD Program of China Scholarship Council (201806230235). We thank ATCC and the NIH for cell lines.

\section{Authors' contributions}

Lai-ping Zhong: he was responsible for the conception and interpretation of the article. Tong-chao Zhao: he provided part of the in vivo data. Si-yuan Liang: she performed the in vitro experiment. Wu-tong Ju: he provided combination treatment strategy. Dong-wang Zhu and Zhi-yuan Zhang: they provided part of the research conception. Zhi-hang Zhou: he was responsible for conception and critical revision of the article.

\section{References}

[1] Kademani D. Oral cancer. Mayo Clin Proc 2007; 82:878-87.

[2] Petersen PE. The World Oral Health Report 2003: continuous improvement of oral health in the $21 \mathrm{st}$ century--the approach of the WHO Global Oral Health Programme. Community Dent Oral Epidemiol 2003; 31 Suppl 1:3-23.

[3] Neville BW, Day TA. Oral cancer and precancerous lesions. CA Cancer J Clin 2002; 52:195-215.

[4] Parkin DM, Bray F, Ferlay J, Pisani P. Global cancer statistics, 2002. CA Cancer J Clin 2005; 55:74-108.

[5] Guo JY, White E. Autophagy, Metabolism, and Cancer. Cold Spring Harb Symp Quant Biol 2016; 81:738.

[6] Amaravadi R, Kimmelman AC, White E. Recent insights into the function of autophagy in cancer. Genes Dev 2016; 30:1913-30.

[7] Kimmelman AC, White E. Autophagy and Tumor Metabolism. Cell Metab 2017; 25:1037-43. 
[8] Muhammad JS, Nanjo S, Ando T, Yamashita S, Maekita T, Ushijima T, et al. Autophagy impairment by Helicobacter pylori-induced methylation silencing of MAP1LC3Av1 promotes gastric carcinogenesis. Int $\mathrm{J}$ Cancer 2017; 140:2272-83.

[9] Shen S, Zhou M, Huang K, Wu Y, Ma Y, Wang J, et al. Blocking autophagy enhances the apoptotic effect of 18beta-glycyrrhetinic acid on human sarcoma cells via endoplasmic reticulum stress and JNK activation. Cell Death Dis 2017; 8:e3055.

[10] Kong P, Zhu X, Geng Q, Xia L, Sun X, Chen Y, et al. The microRNA-423-3p-Bim Axis Promotes Cancer Progression and Activates Oncogenic Autophagy in Gastric Cancer. Mol Ther 2017; 25:1027-37.

[11] Wang J, Liu Z, Hu T, Han L, Yu S, Yao Y, et al. Nrf2 promotes progression of non-small cell lung cancer through activating autophagy. Cell Cycle 2017; 16:1053-62.

[12] Yang A, Rajeshkumar NV, Wang X, Yabuuchi S, Alexander BM, Chu GC, et al. Autophagy is critical for pancreatic tumor growth and progression in tumors with p53 alterations. Cancer Discov 2014; 4:905-13.

[13] Lei Y, Kansy BA, Li J, Cong L, Liu Y, Trivedi S, et al. EGFR-targeted mAb therapy modulates autophagy in head and neck squamous cell carcinoma through NLRX1-TUFM protein complex. Oncogene 2016; 35:4698-707.

[14] Chang I, Wang CY. Inhibition of HDAC6 Protein Enhances Bortezomib-induced Apoptosis in Head and Neck Squamous Cell Carcinoma (HNSCC) by Reducing Autophagy. J Biol Chem 2016; 291:18199-209.

[15] Zhang L, Zhang W, Wang YF, Liu B, Zhang WF, Zhao YF, et al. Dual induction of apoptotic and autophagic cell death by targeting survivin in head neck squamous cell carcinoma. Cell Death Dis 2015; 6:e1771.

[16] Li KC, Hua KT, Lin YS, Su CY, Ko JY, Hsiao M, et al. Inhibition of G9a induces DUSP4-dependent autophagic cell death in head and neck squamous cell carcinoma. Mol Cancer 2014; 13:172.

[17] Yuan L, Zhou C, Lu Y, Hong M, Zhang Z, Zhang Z, et al. IFN-gamma-mediated IRF1/miR-29b feedback loop suppresses colorectal cancer cell growth and metastasis by repressing IGF1. Cancer Lett 2015; 359:136-47.

[18] Xu YH, Li ZL, Qiu SF. IFN-gamma Induces Gastric Cancer Cell Proliferation and Metastasis Through Upregulation of Integrin beta3-Mediated NF-kappaB Signaling. Transl Oncol 2018; 11:182-92.

[19] Li J, Zhang Y, Chen L, Lu X, Li Z, Xue Y, et al. Cervical Cancer HeLa Cell Autocrine Apoptosis Induced by Coimmobilized IFN-gamma plus TNF-alpha Biomaterials. ACS Appl Mater Interfaces 2018; 10:845164 .

[20] Mukherjee KK, Bose A, Ghosh D, Sarkar K, Goswami S, Pal S, et al. IFNalpha2b augments immune responses of cisplatin+5-fluorouracil treated tongue squamous cell carcinoma patients-a preliminary 
study. Indian J Med Res 2012; 136:54-9.

[21] Pagotto A, Pilotto G, Mazzoldi EL, Nicoletto MO, Frezzini S, Pasto A, et al. Autophagy inhibition reduces chemoresistance and tumorigenic potential of human ovarian cancer stem cells. Cell Death Dis 2017; 8:e2943.

[22] Pei G, Luo M, Ni X, Wu J, Wang S, Ma Y, et al. Autophagy Facilitates Metadherin-Induced Chemotherapy Resistance Through the AMPK/ATG5 Pathway in Gastric Cancer. Cell Physiol Biochem 2018; 46:847-59.

[23] Mulcahy LJ, Zahedi S, Griesinger AM, Morin A, Davies KD, Aisner DL, et al. Autophagy inhibition overcomes multiple mechanisms of resistance to BRAF inhibition in brain tumors. Elife. 2017; 6 .

[24] Burman C, Ktistakis NT. Autophagosome formation in mammalian cells. Semin Immunopathol 2010; 32:397-413.

[25] Kimura S, Noda T, Yoshimori T. Dissection of the autophagosome maturation process by a novel reporter protein, tandem fluorescent-tagged LC3. Autophagy 2007; 3:452-60.

[26] Zaidi MR. The Interferon-Gamma Paradox in Cancer. J Interferon Cytokine Res. 2019; 39:30-8.

[27] Zaidi MR, Merlino G. The two faces of interferon-gamma in cancer. Clin Cancer Res. 2011; 17:611824.

[28] Rakshit S, Chandrasekar BS, Saha B, Victor ES, Majumdar S, Nandi D. Interferon-gamma induced cell death: Regulation and contributions of nitric oxide, cJun N-terminal kinase, reactive oxygen species and peroxynitrite. Biochim Biophys Acta 2014; 1843:2645-61.

[29] Hubackova S, Kucerova A, Michlits G, Kyjacova L, Reinis M, Korolov O, et al. IFNgamma induces oxidative stress, DNA damage and tumor cell senescence via TGFbeta/SMAD signaling-dependent induction of Nox4 and suppression of ANT2. Oncogene 2016; 35:1236-49.

[30] Braumuller H, Wieder T, Brenner E, Assmann S, Hahn M, Alkhaled M, et al. T-helper-1-cell cytokines drive cancer into senescence. Nature 2013; 494:361-5.

[31] Creagan ET, Ahmann DL, Long HJ, Frytak S, Sherwin SA, Chang MN. Phase II study of recombinant interferon-gamma in patients with disseminated malignant melanoma. Cancer Treat Rep. 1987; 71:843-4.

[32] Ernstoff MS, Trautman T, Davis CA, Reich SD, Witman P, Balser J, et al. A randomized phase I/II study of continuous versus intermittent intravenous interferon gamma in patients with metastatic melanoma. $J$ Clin Oncol 1987; 5:1804-10.

[33] Kopp WC, Smith JN, Ewel CH, Alvord WG, Main C, Guyre PM, et al. Immunomodulatory effects of interferon-gamma in patients with metastatic malignant melanoma. $\mathrm{J}$ Immunother Emphasis Tumor 
Immunol. 1993; 13:181-90.

[34] Schiller JH, Pugh M, Kirkwood JM, Karp D, Larson M, Borden E. Eastern cooperative group trial of interferon gamma in metastatic melanoma: an innovative study design. Clin Cancer Res 1996; 2:29-36.

[35] Gade P, Ramachandran G, Maachani UB, Rizzo MA, Okada T, Prywes R, et al. An IFN-gammastimulated ATF6-C/EBP-beta-signaling pathway critical for the expression of Death Associated Protein Kinase 1 and induction of autophagy. Proc Natl Acad Sci USA 2012; 109:10316-21.

[36] Poillet-Perez L, White E. Role of tumor and host autophagy in cancer metabolism. Genes Dev 2019; 33:610-9.

[37] Bento CF, Renna M, Ghislat G, Puri C, Ashkenazi A, Vicinanza M, et al. Mammalian Autophagy: How Does It Work? Annu Rev Biochem 2016; 85:685-713.

[38] Zheng Y, Su C, Zhao L, Shi Y. Chitosan nanoparticle-mediated co-delivery of shAtg-5 and gefitinib synergistically promoted the efficacy of chemotherapeutics through the modulation of autophagy. $J$ Nanobiotechnology 2017; 15:28.

[39] Zhong J, Dong X, Xiu P, Wang F, Liu J, Wei H, et al. Blocking autophagy enhances meloxicam lethality to hepatocellular carcinoma by promotion of endoplasmic reticulum stress. Cell Prolif 2015; 48:691-704.

[40] Bryant KL, Stalnecker CA, Zeitouni D, Klomp JE, Peng S, Tikunov AP, et al. Combination of ERK and autophagy inhibition as a treatment approach for pancreatic cancer. Nat Med 2019; 25:628-40.

[41] Kim DH, Kim H, Choi YJ, Kim SY, Lee JE, Sung KJ, et al. Exosomal PD-L1 promotes tumor growth through immune escape in non-small cell lung cancer. Exp Mol Med 2019; 51:1-13.

\section{Figures}


A

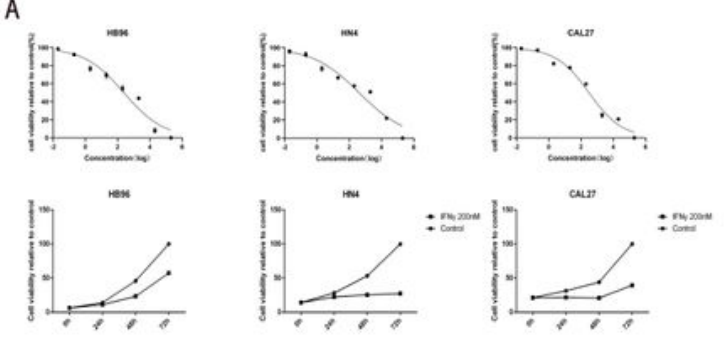

C
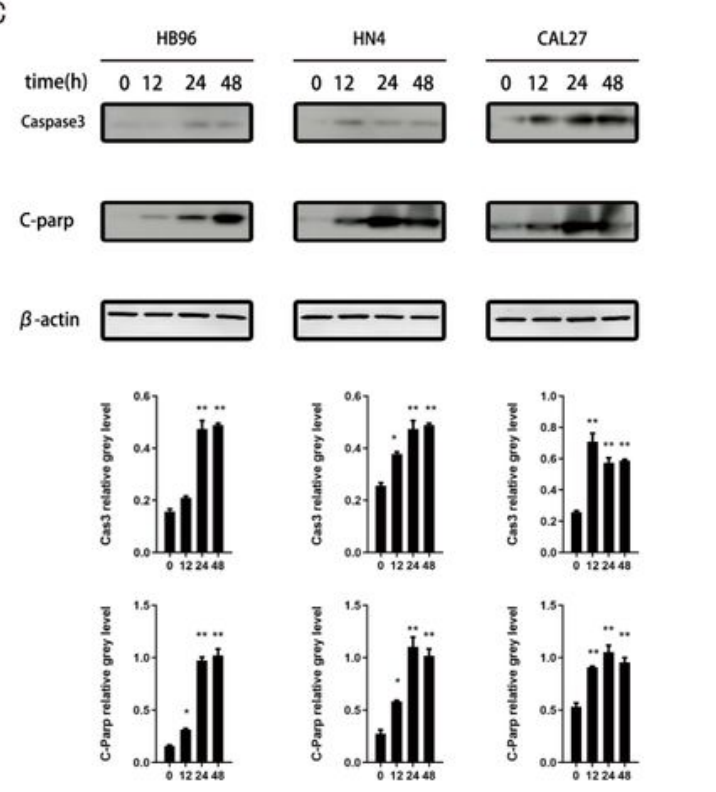

$E$

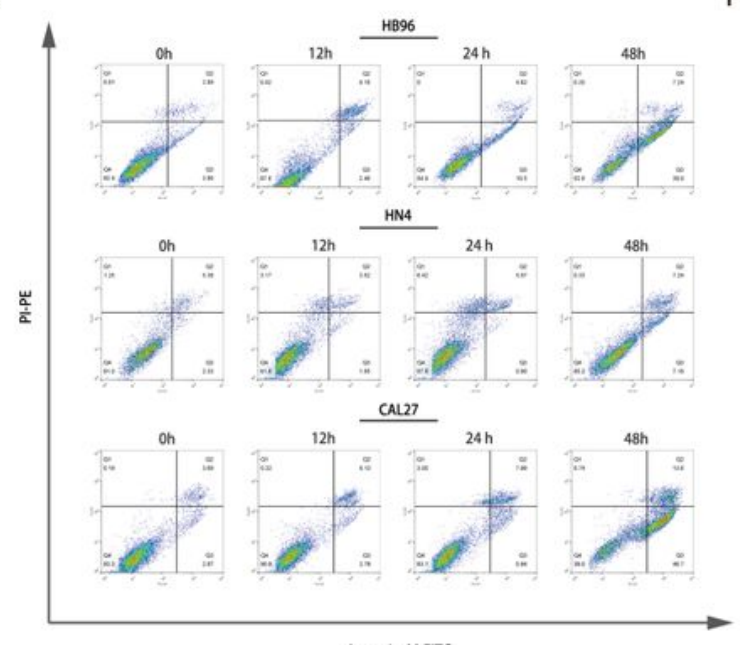

Annexin-V FITC
B

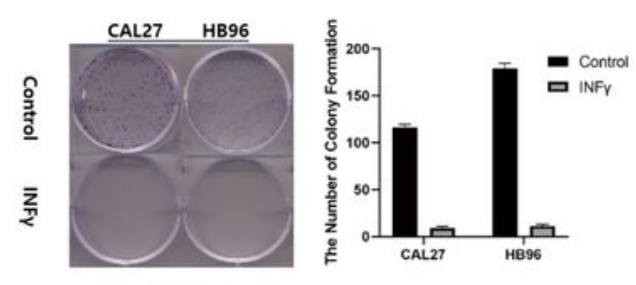

D
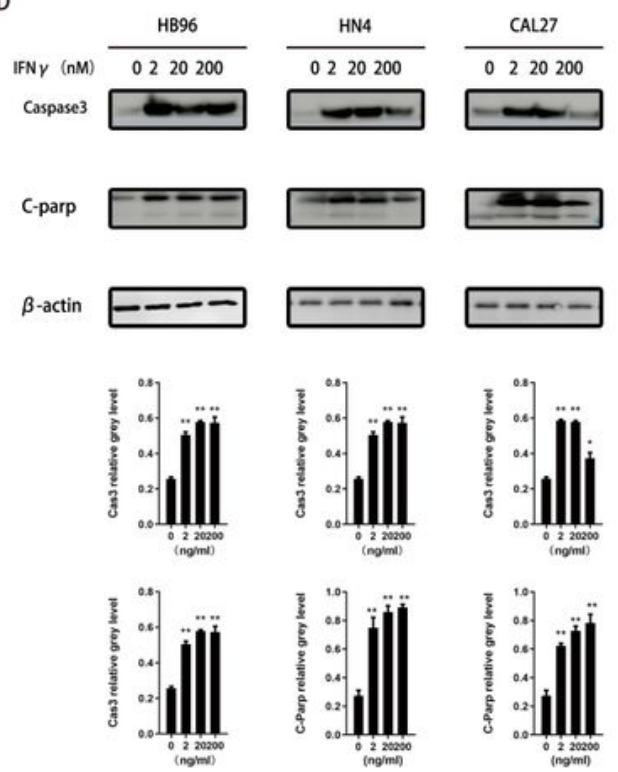

$\mathrm{F}$

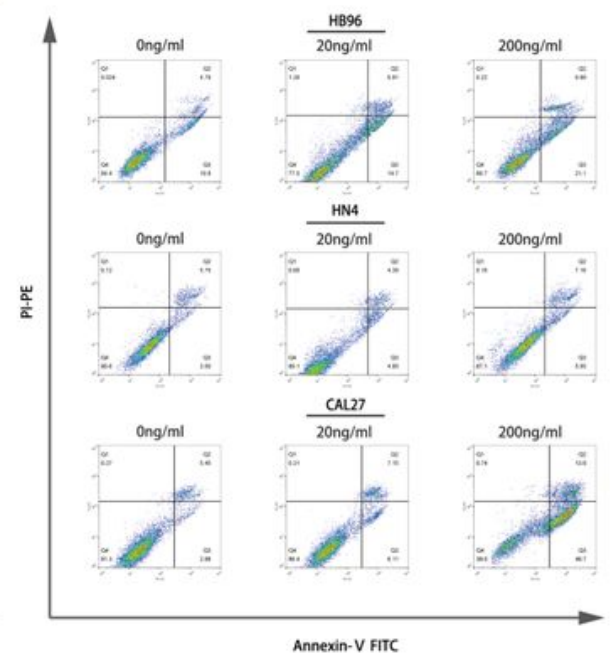

\section{Figure 1}

IFNy exerts cytotoxicity and induces apoptosis in HB96, HN4, and CAL27 cells. (A) After the treatment of different concentrations of IFNy within $72 \mathrm{~h}$, cell viability was assessed by using an MTT assay. IC50 of IFNy was measured in HB96, HN4, and CAL27 cells. The cells were incubated with $200 \mathrm{ng} / \mathrm{ml}$ of IFNy or PBS for multiple time points, and then cell viability was measured using the MTT assay. (B) IFNY inhibited colony formation in CAL27 and HB96 cells. Cells were incubated in complete medium with or 
without IFNy $(200 \mathrm{ng} / \mathrm{ml})$ for $7 \mathrm{~d}$ and stained by $0.5 \%$ crystal violet. Relative colony formation is represented in the bar graph. (C) Western blot analysis showed that PARP and caspase- 3 were upregulated after $200 \mathrm{ng} / \mathrm{ml} \mathrm{IFNy}$ treatment for the indicated time points in the HB96, HN4, and CAL27 cells. Membranes were probed with a beta-actin antibody as a loading control. (D) Western blotting showed increased cleaved-PARP and activation of caspase-3 after treatment with indicated concentrations of IFNy for $48 \mathrm{~h}$ in the HB96, HN4, and CAL27 cells. (E) After IFNy treatment $(200 \mathrm{ng} / \mathrm{ml})$ for indicated time points, apoptotic cell rates were analyzed by flow cytometry. (F) HN4 and HN30 cells were treated with indicated concentrations of IFNY for $48 \mathrm{~h}$ before staining with Annexin $\mathrm{V}$ and propidium iodide $(\mathrm{PI})$, and the apoptotic rates were determined by flow cytometry. All the $P$ values were compared with the control *: $P<0.05, * *: P<0.01$. 
A
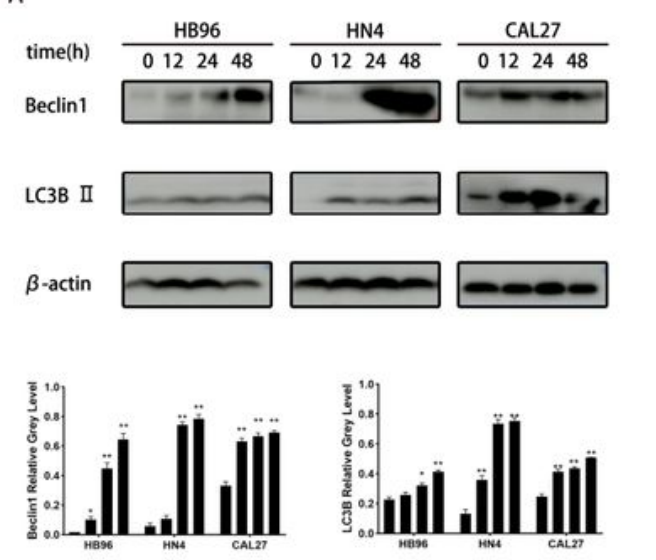

B
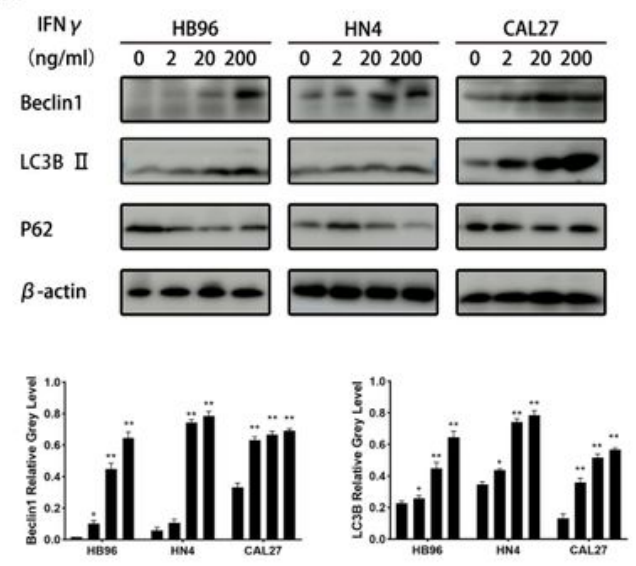

C

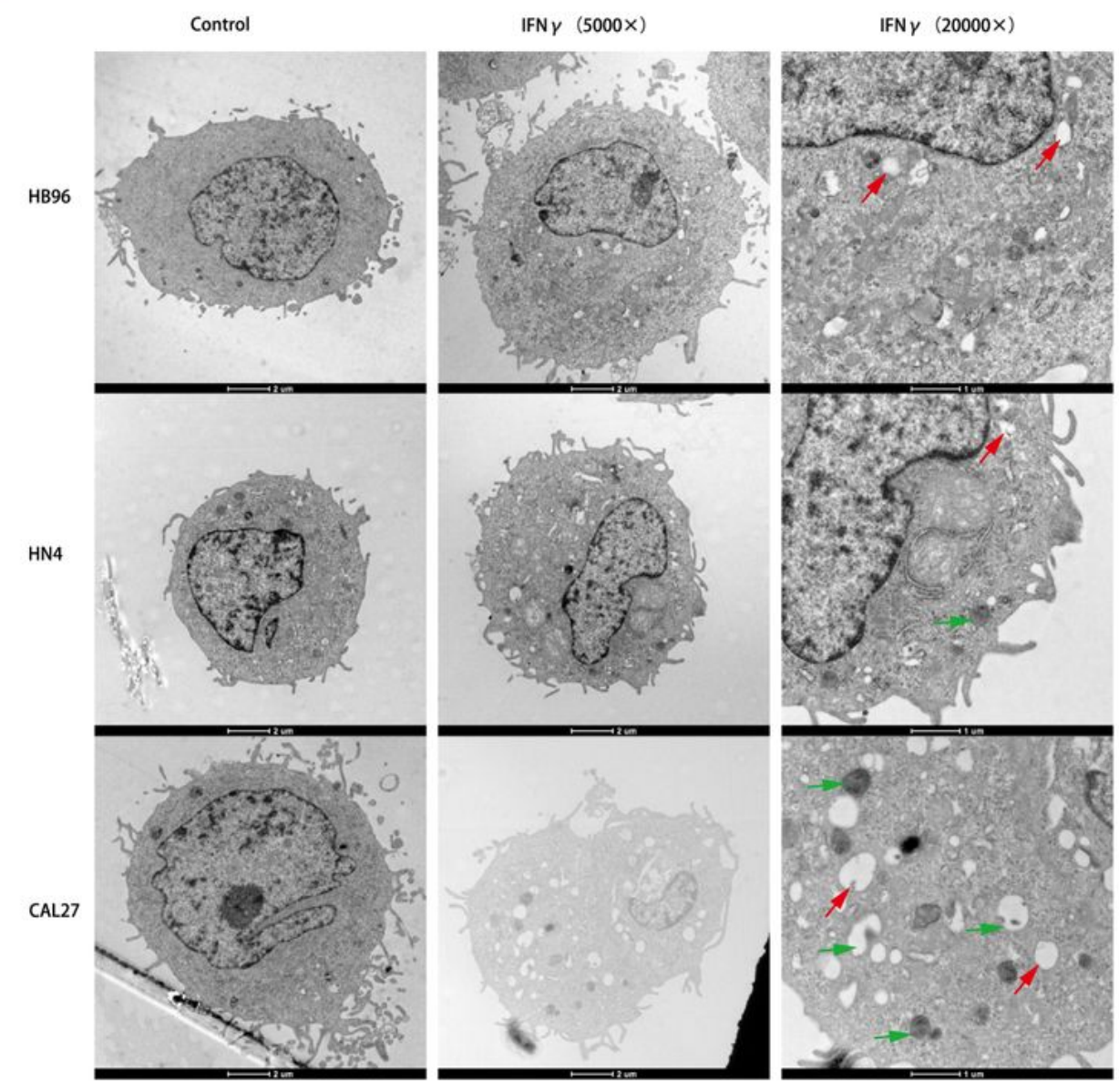

\section{Figure 2}

IFNy induces autophagy in OSCC cells. (A, B) IFNy promoted Beclin 1 and LC3B II expression in a concentration- and time-dependent manner in HB96, HN4, and CAL27 cells. (C) Representative transmission electron microscopy (TEM) images revealing the formation of phagophores (red arrow), autophagosomes, and autolysosomes (green arrow) after IFNy $(200 \mathrm{ng} / \mathrm{ml})$ treatment for $24 \mathrm{~h}$. All the P values were compared with the control *: $\mathrm{P}<0.05, * *$ : $\mathrm{P}<0.01$. 
A

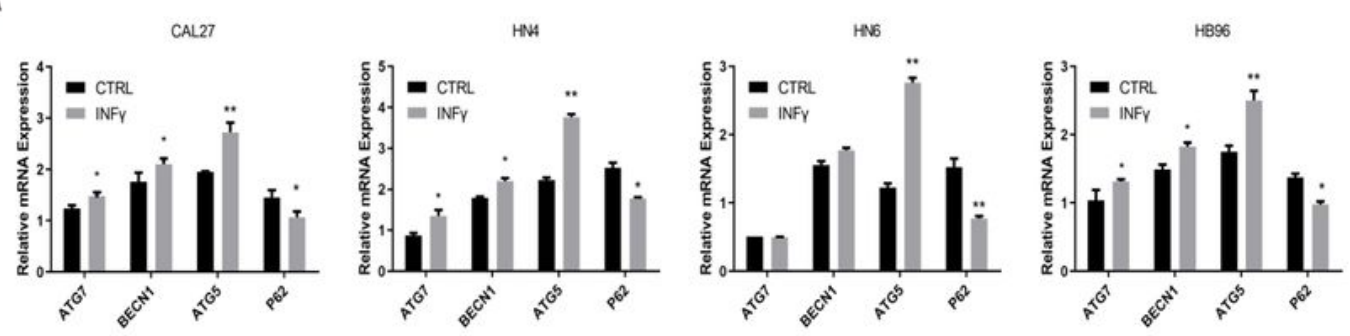

B
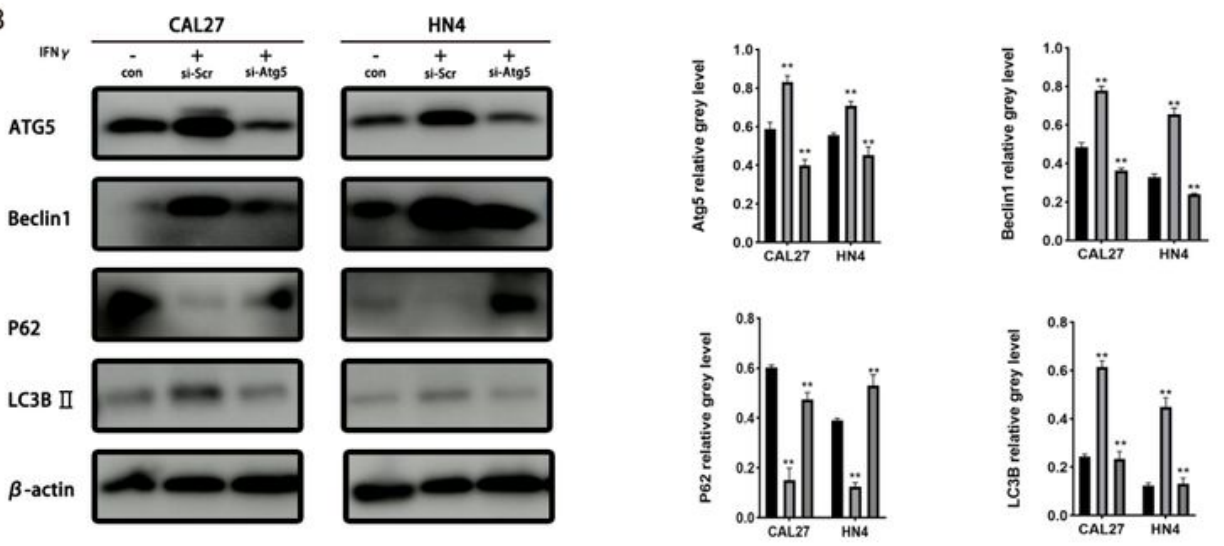

C
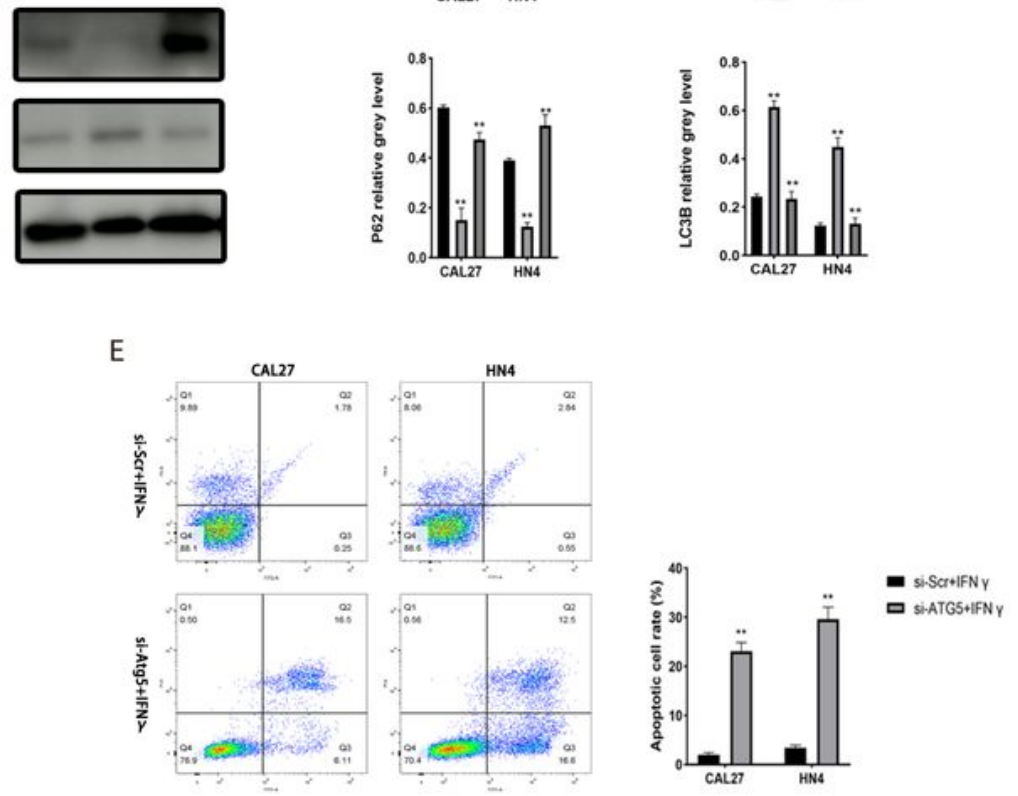

D
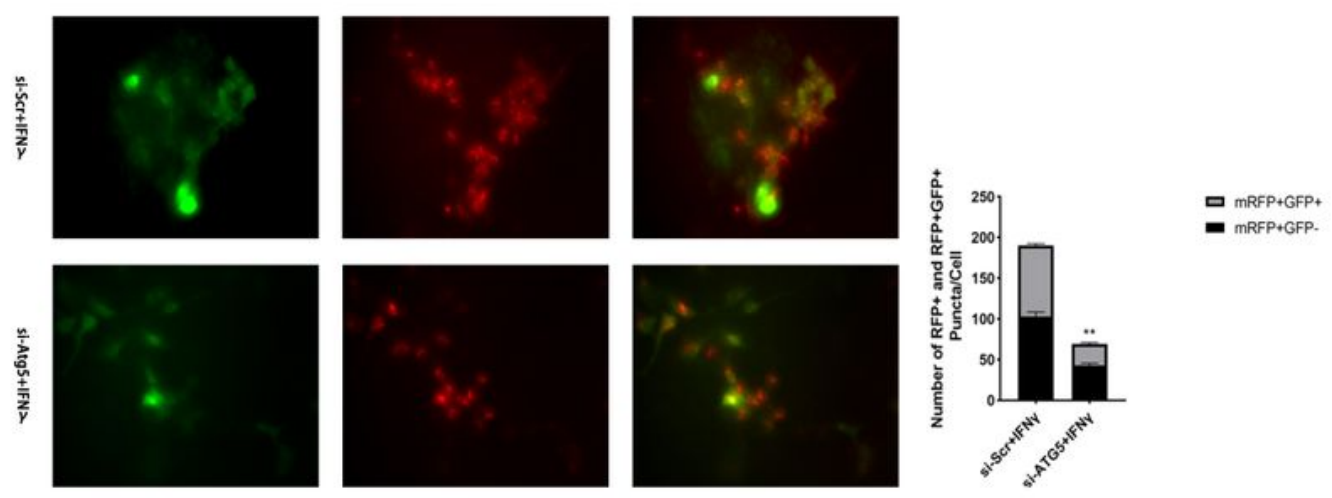

\section{Figure 3}

ATG5 is necessary for IFNY-induced autophagy in OSCC cells. (A) ATGs and P62 mRNA expression level in HB96, CAL27, HN4, and HN6 cells treated with or without $200 \mathrm{ng} / \mathrm{ml}$ IFNy was analyzed by real-time PCR assay. (B) CAL27 and HN4 cells were transfected with siRNAs targeting ATG5 for $48 \mathrm{~h}$ and then treated with IFNy $(200 \mathrm{ng} / \mathrm{ml})$ for $48 \mathrm{~h}$. Expression of ATG5, P62, Beclin 1, and LC3B II was detected using a western blot assay. (C) Efficiency for ATG5 gene silencing was confirmed by western blot assay. (D) 
ATG5-/- CAL27 and ATG5-/- HN4 cells were transfected with GFP-mRFP-LC3 construct for $48 \mathrm{~h}$ and then incubated in IFNy $(200 \mathrm{ng} / \mathrm{ml})$ for $48 \mathrm{~h}$. The merged color was observed. Red or yellow puncta of different stage LC3B were calculated by quantitative analysis and reported as the mean \pm SD. (E) After incubation in IFNy $(200 \mathrm{ng} / \mathrm{ml})$ for $48 \mathrm{~h}$, the apoptotic cell rate was compared between the OSCC cells transfected with ATG5 siRNA and control siRNA, which was measured by flow cytometry analysis with Annexin $V$ and $\mathrm{PI}$ staining. All the $\mathrm{P}$ values were compared with the control *: $\mathrm{P}<0.05, * *$ : $\mathrm{P}<0.01$.

A

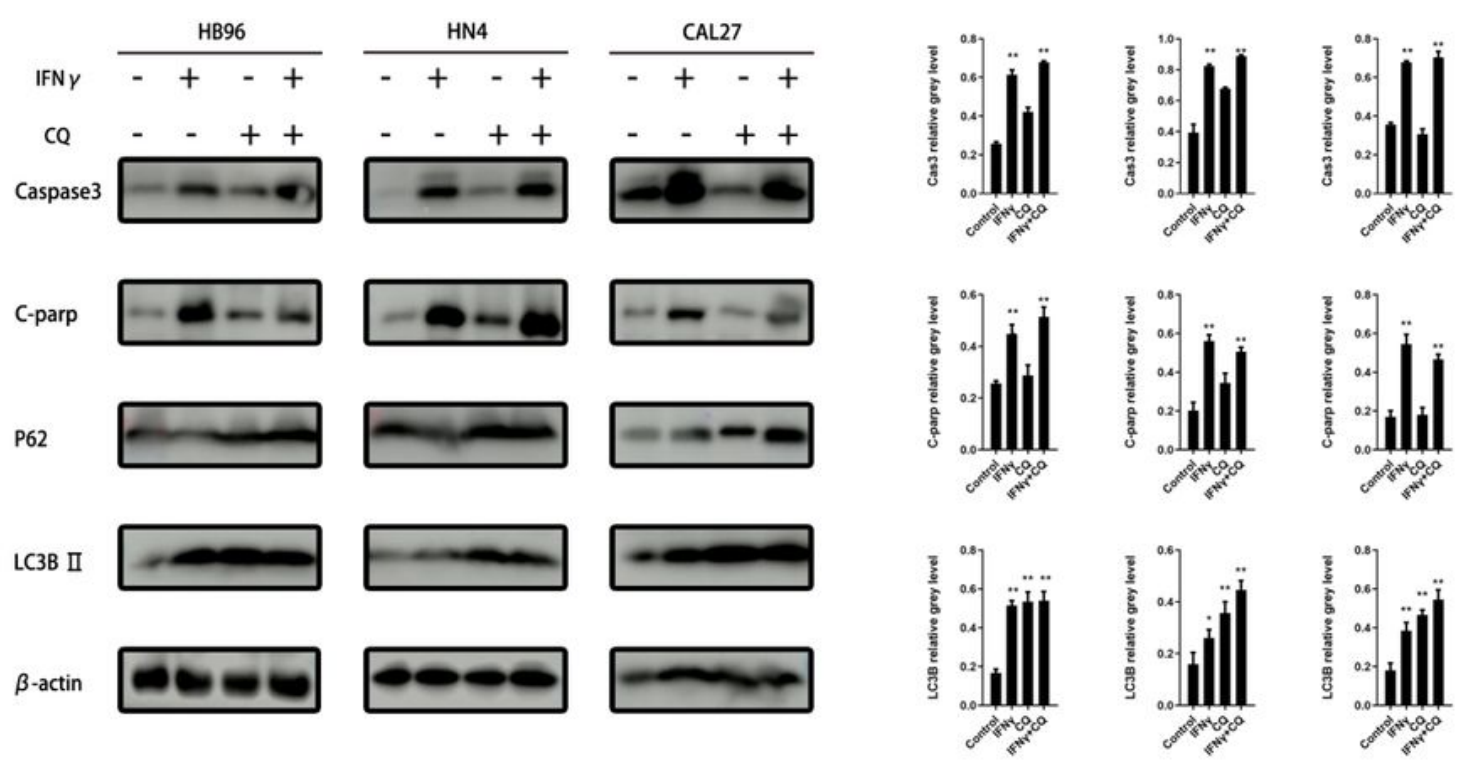

B

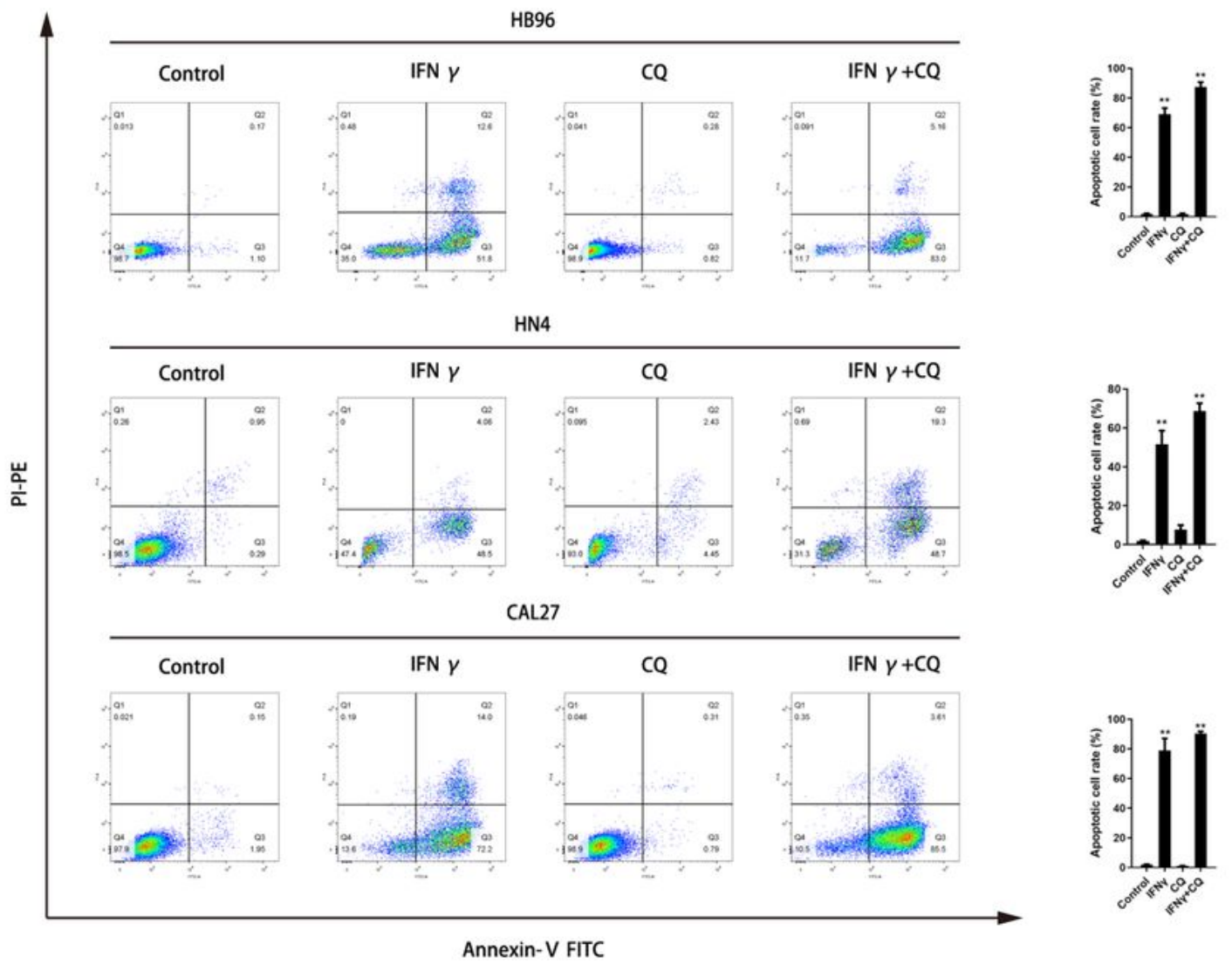

Figure 4 
Synergistic effect of autophagy inhibitor (CQ) in IFNy-induced apoptosis in OSCC cells. (A) HB96, HN4, and CAL27 cells were stimulated by IFNY $(200 \mathrm{ng} / \mathrm{ml})$ in the presence or absence of CQ $(10 \mathrm{uM})$ for $48 \mathrm{~h}$. Expression of apoptosis and autophagy relative protein, including caspase-3, cleaved-PARP, P62, and LC3B II was assessed by a western blot assay. Quantification of the proteins relative to beta-actin OD values is presented. (B) IFNy-induced apoptosis was synergized by CQ treatment in the HB96, HN4, and CAL27 cells, which was measured by flow cytometry analysis of Annexin V and PI staining. All the $P$ values were compared with the control. *: $\mathrm{P}<0.05, * *$ : $P<0.01$.

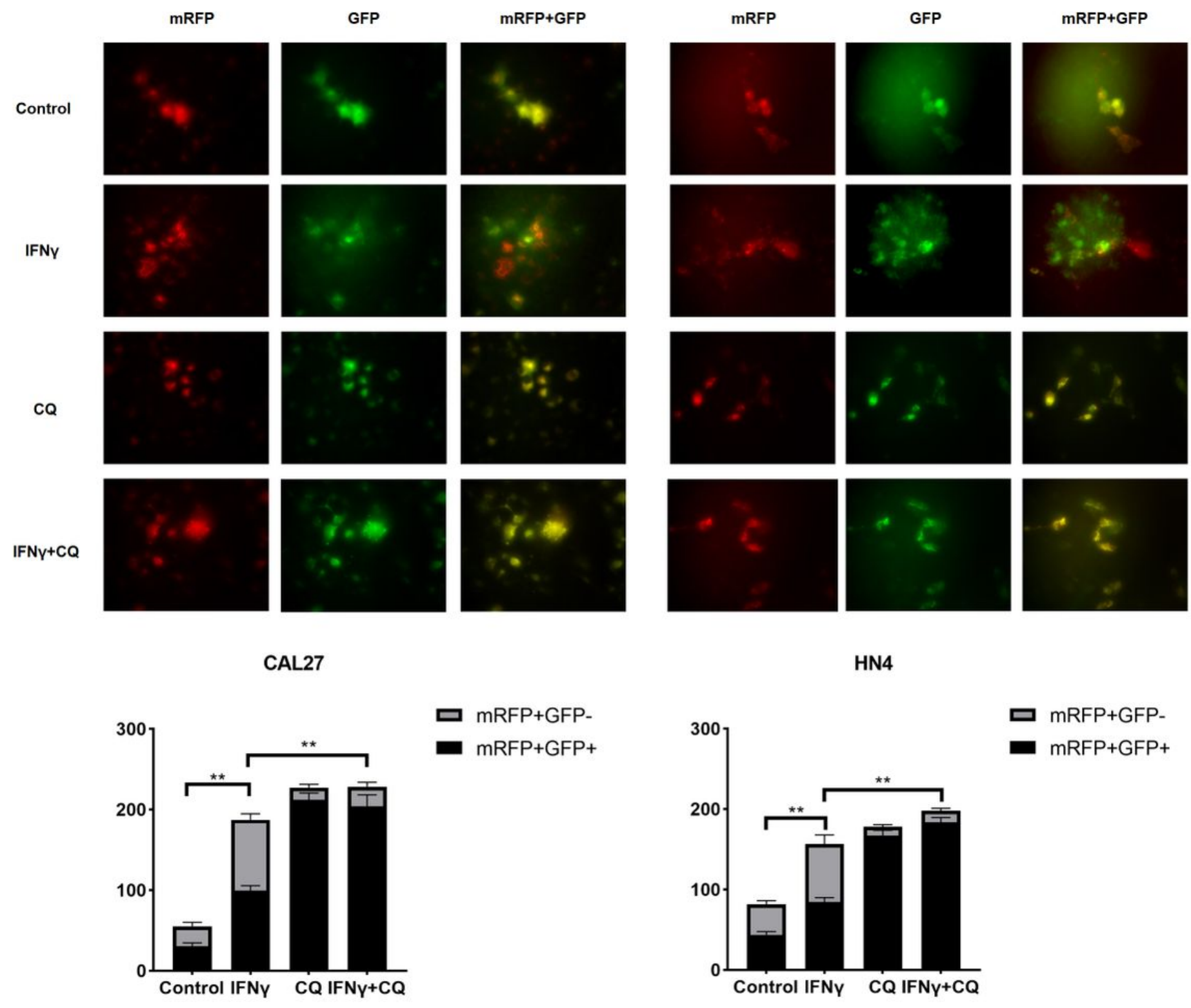

Figure 5

Autophagy flux assay was performed in the HN4 and CAL27 cells treated with IFNy (200 $\mathrm{ng} / \mathrm{ml}$ for $48 \mathrm{~h})$ using a tandem fluorescent-tagged LC3B reporter plasmid (GFP-mRFP-LC3B). The yellow fluorescence puncta represented the merging image of green and red fluorescence in autophagosomes, which 
indicated impaired autophagy. The red fluorescence puncta alone after fusion represented complete autophagic flux. Quantitative analysis of red and yellow LC3 puncta was reported as mean \pm SD. All the $P$ values were compared with the control. *: $\mathrm{P}<0.05$, **: $\mathrm{P}<0.01$.

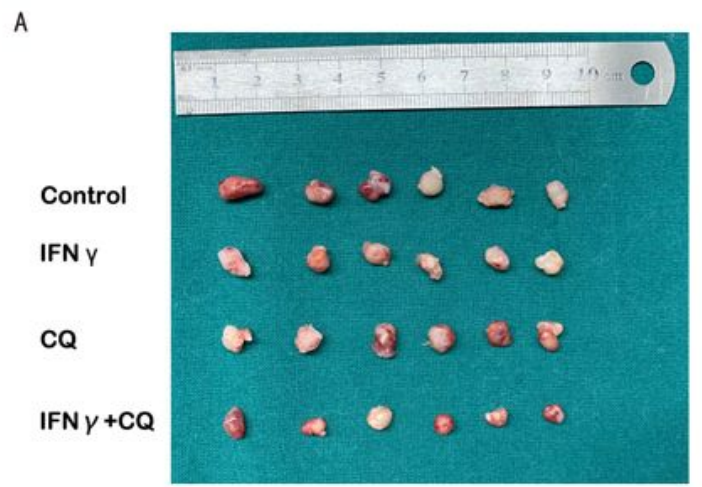

B

C

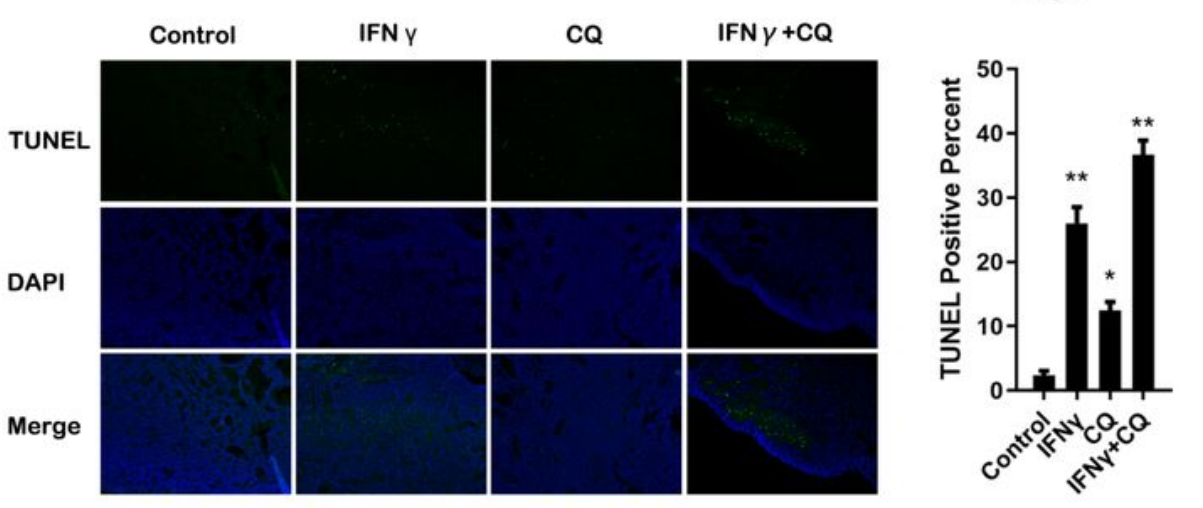

D

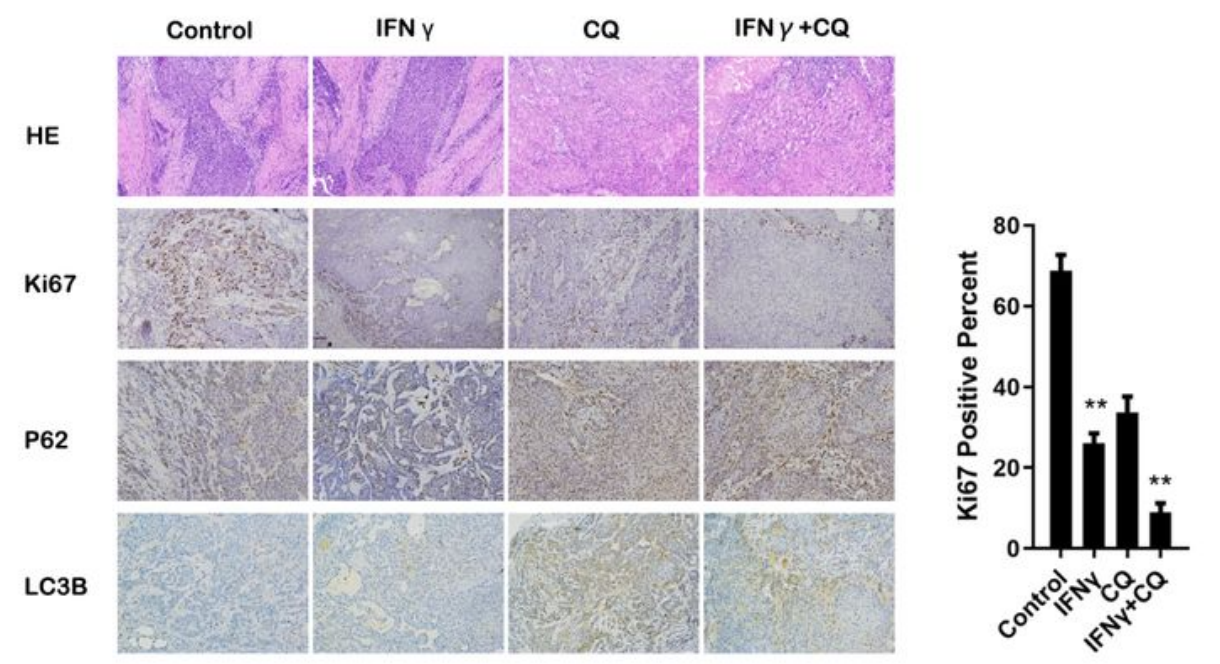

Figure 6

Synergistic effect of CQ and IFNY in an OSCC tumor xenograft model. After establishing the OSCC tumor xenograft model, 24 nude mice were randomly divided into control, IFNy, CQ, and IFNy plus CQ groups 
(six mice per group). Prescription: IFNy (10, 000 IU per mouse per day, i.p), CQ (30 mg/kg per day, i.g), IFNy plus CQ, and control ( $0.9 \%$ saline, i.p). All mice were sacrificed 21 days after therapy. (A) Representative images of subcutaneous tumors after treatment. (B) The tumor volumes were evaluated among the four groups. (C) The percentage of TUNEL-positive cells was assessed in formalin-fixed paraffin embedding sections of tumors in each group. Magnification: $\times 200$. (D) Representative images of tumors from xenografts using HE staining and immunohistochemical staining against Ki67, P62, and LC3B. Magnification: $\times 200$. All the $P$ values were compared with the control. *: $P<0.05, * *: P<0.01$. 